\title{
COMO NÃO ESCREVER UM ARTIGO MÉDICO
}

${ }^{1}$ Jacqueline Messias dos Santos

${ }^{1}$ Gildenir Carolino Santos

Universidade Estadual de Campinas ${ }^{1}$

\section{Correspondência}

Jacqueline Messias dos Santos

Universidade Estadual de Campinas

Campinas - SP - Brasil

E-mail: jacquelinemessiasds@gmail.com

ORCID: https://orcid.org/0000-0001-9036-3021

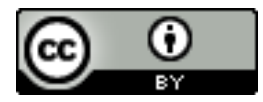

JITA: AC. Relationship of LIS with other fields 


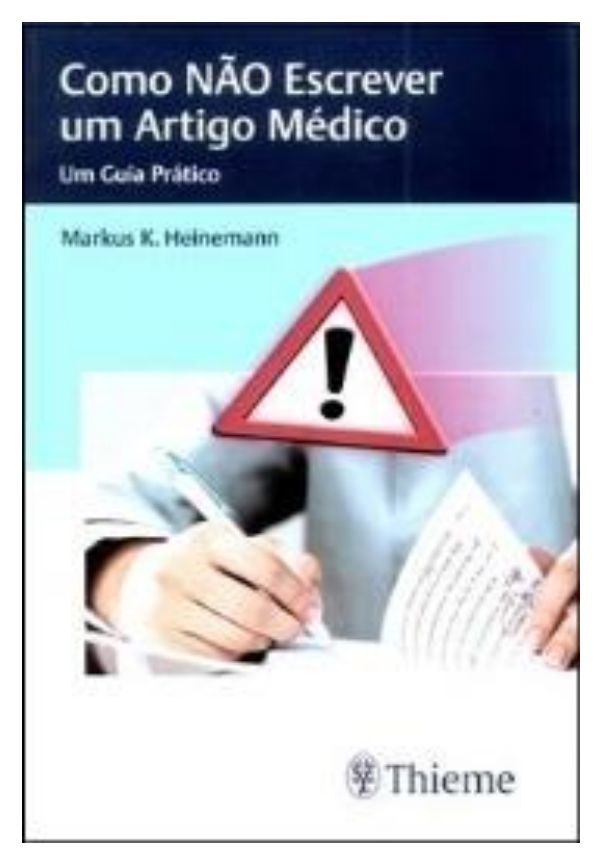

HEINEMANN, Markus K. Como não escrever um artigo médico: um guia prático. Rio de Janeiro: Thieme, 2016. 94 p. ISBN 978-85-67661-19-3.

O livro escrito por Markus K. Heinemann, Phd e especialista em cirurgia vascular, torácica e cardíaca, pela Universitatsmedizin Mains, na Alemanha, tem por objetivo apontar os erros mais comuns ao se escrever um artigo médico, e assim, orientar a escrita de publicação científica da área, detalhando, do seu ponto de vista, os principais tópicos e dúvidas que podem surgir ao longo do processo de criação.

$\mathrm{Na}$ sua experiência como editor-chefe da revista científica The Thoracic and Cardiovascular Surgeon, entrou em contato com diversos tipos de artigos com erros recorrentes e, a partir daí, surgiu a ideia para um guia passo a passo de como evitá-los, levando em consideração todos os pormenores que a escrita científica e acadêmica exige. Levando em consideração que, muitas vezes, a linguagem de um artigo científico é extremamente complexa e por vezes inacessível, o autor propõe escrever algo simples que seja de fácil acesso e entendimento para o leitor de modo que o leitor também possa escrever artigos médicos com linguagem clara e acessível. As falhas dos artigos, segundo o autor, são de ordens editoriais e repetidas recorrentemente, nesse sentido, o manual contribui de forma significativa para o entendimento de todo o processo de elaboração de um artigo médico, desde a escrita à publicação.

A obra está dividida em oito capítulos, abordando os seguintes temas:

1. Introdução

2. Porque os editores aceitam/rejeitam manuscritos

3. Tipos de artigos científicos

4. Componentes do manuscrito

5. Processo de revisão e correções

6. Ética de publicação 
7. É bom saber (cadeia de produção, indexação, fatores e similares, o que as publishers fazem, open access, glossário)

\section{Conselhos finais}

Dessa forma, os oito capítulos abordam 22 pontos fundamentais relacionados à publicação de um artigo científico de Medicina, contendo 94 páginas compostas para uma leitura confortável e bem-humorada, ilustradas com bons e maus exemplos. O referente livro foi publicado em 2016 pela editora médica e científica Thieme, com sede também no Rio de Janeiro.

Para dar início às abordagens temáticas, o autor analisa os principais motivos pelos quais os artigos são rejeitados utilizando como base um artigo escrito por Georges Bordage, do Departamento de Educação Médica da Universidade de Illinois, em Chicago nos Estados Unidos. Esse artigo foi escrito através da análise de comentários de revisores de artigos científicos e, a partir disso, foi possível elaborar uma lista com os principais itens que causaram sua rejeição, que é parcialmente apresentada ao leitor. Nessa lista, consta que os principais erros estão relacionados a métodos estatísticos, inadequados, mal interpretados ou de amostra insuficiente. Outro fator descrito que também contribui para a rejeição do artigo é a falta de relevância ou coerência dos tópicos abordados.

Em seguida, o autor faz um resumo dos tipos de artigo científicos possíveis de serem publicados na área, são eles: artigo original, metanálise, artigo de revisão, how-to-do, relato de caso e carta ao editor. Com isso, faz uma abordagem que, apesar de breve, é muito instrutiva, sobre como os diferentes tipos de artigo se dão dentro da área médica e suas principais características, bem como observações pertinentes sobre o que fazer ou não em cada uma delas. É importante ressaltar que o autor procura colocar bons e maus exemplos para ilustrar o tópico que está abordando, contribuindo para um melhor entendimento por parte do leitor, assim como usa de tabelas e gráficos para deixar mais claro o que é considerado correto e errado nos artigos. Além disso, o autor também faz recomendações de plataformas de consultas, estudos, sites e outros materiais para além do manual como sugestões que o leitor pode recorrer e consultar.

Dando continuidade ao tema do livro, o autor dedica todo o capítulo 4 a descrever o que fazer e o que não fazer, com detalhes. O interessante desse capítulo é a linguagem objetiva e clara usada para abordar tudo que é feito comumente e que poderia ser evitado. Nesse capítulo, todo o conteúdo de um artigo, desde os autores e o título até as referências, é descrito minuciosamente de modo sucinto e prático, através dos bons e maus exemplos como já foi comentado anteriormente.

Após essa abordagem, o capítulo seguinte trata dos processos de correção e revisão, uma etapa de suma relevância e centralidade na elaboração de um artigo. Ainda trabalhando com exemplos positivos e negativos, o leitor é apresentado às melhores maneiras de como \begin{tabular}{l} 
(C) RDBCI: Rev. Digit. Bibliotecon. Cienc. Inf. \\
\hline
\end{tabular} 
responder a uma devolutiva do trabalho e sinalizar as mudanças do texto. $\mathrm{O}$ autor explica o papel do revisor e do editor nesse processo e as variáveis que podem interferir na revisão. Essa explicação é de extrema importância para o leitor, que pode não ter conhecimento sobre como a correção funciona e, a partir do momento que entra em contato com essas informações que são deixadas de forma clara no livro, pode com certeza desenvolver um artigo melhor.

O capítulo 6, por sua vez, é dedicado à ética de publicação. $\mathrm{O}$ autor divide a problemática da ética em dois tópicos: o backgound ético, que abarca os processos que deveriam ter sido feitos no decorrer da pesquisa, como em caso de pesquisa com pessoas, que precisam de aprovação do comitê de ética; e o comportamento dos autores em relação ao processo de publicação, que se tornou algo corriqueiro nas publicações, mas que se difere do que é conhecido como plágio, autoplágio e fabricação de dados, segundo o autor, que explica a diferença entre todos e como atrapalham as publicações.

Dando continuidade, o capítulo 7, denominado "É bom saber", traz informações muito interessantes sobre o que acontece com o artigo depois da aprovação, que é uma etapa fundamental para todo o processo de publicação, mas que muitos desconhecem. Nesse sentido, o autor explica como funciona a cadeia de produção de um artigo, os papéis do editor-chefe e do editor de produção, a importância do layout e da editoração dos artigos. Em seguida, explica a indexação, o que é o DOI (Digital Object Identifier), os fatores de impacto das revistas principalmente os fatores de relevância para a área médica e, também, o que as publishers fazem. Além de todas essas informações relevantes, o autor aborda, ainda, a questão o open access, um tipo de prática que permite livre acesso online ao artigo, mas que contém especificidades de cobrança pela publicação que merecem atenção.

Por fim, o autor destina o último capítulo para conselhos finais de planejamento e incentivo à participação na produção científica na área médica, como uma forma de amarrar o todo abordado e concluir de forma geral as diretrizes já ditas.

Esta obra é muito rica e valiosa a todos com qualquer interesse em publicação científica. É direcionada a estudantes de medicina ou cientistas atuantes na área que desejam percorrer a trilha como autores, revisores ou até mesmo editores, que podem consultar essa obra como um guia prático para essa finalidade. Até mesmo bibliotecários que atuam na área médica e editoração de publicações científicas, além de pesquisadores de áreas correlatas, poderão se beneficiar dessa tão bem elaborada obra escrita por Markus K. Heinemann. 

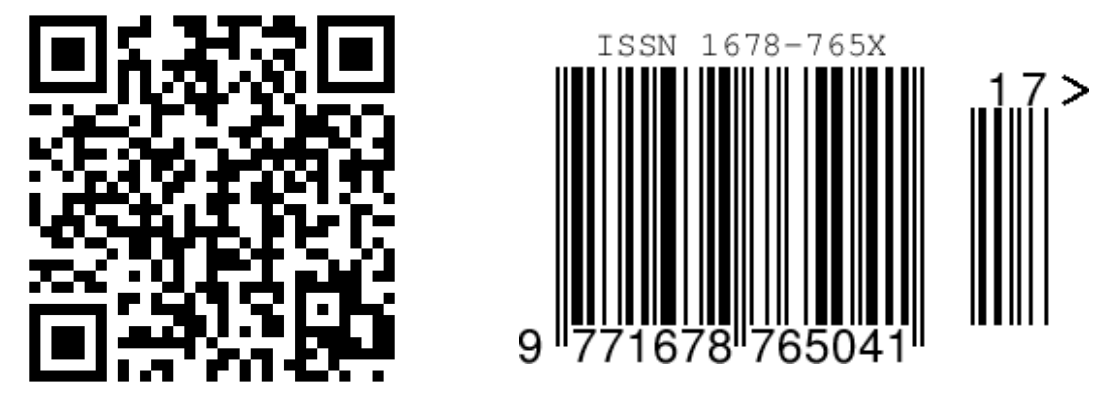